\title{
Tobramycin nephrotoxicity. A prospective clinical study
}

\author{
Antonio Coca \\ M.D.
Alberto Martinez
M.D. \\ ElADIO SORIANO
M.D.
}

\author{
JUAN BLADE \\ M.D.
}
FERnANDo SEgura
M.D.

MANUEL Ribas-Mundo

M.D.

\section{Departamento de Medicina Interna, Clínica Médica B. Hospital Clínico, Facultad de Medicina, Barcelona, Spain}

\begin{abstract}
Summary
The nephrotoxicity of tobramycin given at a dose of $4.5 \mathrm{mg} / \mathrm{kg} /$ day for a period of 12 days to a group of 90 patients with a mean age of 62.9 years was studied. Toxicity was determined on the basis of 3 main criteria (oliguria $<400 \mathrm{ml} / 24 \mathrm{hr}$, serum creatinine $0.4 \mathrm{mg}$ increase over a minimum basal level of $1.2 \mathrm{mg} / 100 \mathrm{ml}$, BUN $5 \mathrm{mg}$ increase over a minimum of $25 \mathrm{mg} / 100 \mathrm{ml}$ ); and 3 minor criteria (proteinuria, microhaematuria and cylindruria). These parameters were determined before treatment at $7,10,14,17,21$, and 30 days afterwards. The age and coexistence of factors such as hypertension, diabetes, anaemia, cardiac insufficiency, shock and dehydration were considered. Nephrotoxicity level ranges from $3 \cdot 3$ to $38.8 \%$ depending on the criterion used, and is related to hypertension $(P<0.001)$, age $(P<0.005)$ and association with ampicillin $(P<0.005)$. Nephrotoxicity was reversible spontaneously in $96.7 \%$ of the cases and no differences have been observed between patients with moderate renal insufficiency and those with normal renal function on the initiation of treatment.
\end{abstract}

\section{Introduction}

Although the toxic effects of the aminoglycosides on the nervous system (eighth nerve), liver, skin and digestive tract are well known, the effects on the kidney are also of importance (Bendush and Weber, 1976). Renal damage may occur by both direct nephrotoxicity or hypersensitivity; the former being dose-related, the latter not. The possible abnormal activation, by the antibiotic, of the renin-angiotensin system and subsequent permanent cortical vasoconstriction in an oliguric phase has also been suggested (Hollenberg et al., 1970; Alcazar et al., 1976).
Tobramycin (nebramycin factor 6) is a relatively new aminoglycoside with an antimicrobial activity similar to that of gentamicin, although with possibly a higher efficacy against Pseudomonas and a lower activity against Staphylococcus (Preston and Wick, 1971; Britt et al., 1972; Delbene and Farrar, 1972; Hof, Schiotz and Paulsen, 1974; Jaffe et al., 1974; Duncan and Penner, 1975); it may be especially useful for pulmonary (Pennington and Reynolds, 1973) and urinary infections (Landes et al., 1975). As in the case of gentamicin, this new aminoglycoside is not devoid of toxicity, as shown by experiments conducted in animals (Wick and Welles, 1968; Welles et al., 1973; De Rosa et al., 1974) and in man (Tobias, Whitehouse and Wrigley, 1976; Lockwood and Bower, 1973). However, some animal experiments seem to indicate a lower nephrotoxicity of tobramycin as compared to gentamicin (Wick and Welles, 1968; Welles et al., 1973).

The aim of this study was the determination of tobramycin nephrotoxicity in humans.

\section{Patients and methods}

Tobramycin was given to a group of 90 patients suffering from various infectious diseases. Their ages ranged between 17 and 97 years, with a mean of 62.9 years. An i.m. dosage of $4.5 \mathrm{mg} / \mathrm{kg} /$ day given as $1.5 \mathrm{mg} / \mathrm{kg}$ every $8 \mathrm{hr}$ was administered for a period of 12 days in every case. When serum creatinine levels were higher than $1.2 \mathrm{mg} / 100 \mathrm{ml}$ (normal range from 0.8 to $1.2 \mathrm{mg} / 100 \mathrm{ml}$ ) dosage was adjusted according to a simplified nomogram based on Benner, Kranhold and Bush (1969): Dose every $8 \mathrm{hr}=$ normal dose/serum creatinine (in $\mathrm{mg} / 100 \mathrm{ml}$ ).

The following were determined before therapy: blood count, serum blood sugar, proteins, electro- 
lytes, creatinine, BUN, plasma and urine osmolarity, quantitative proteinuria and urinary sediment. Factors which might contribute to renal disease, such as arterial hypertension, diabetes, cardiac insufficiency, dehydration, anaemia and shock as well as renal insufficiency (creatinine level $>1.4$ $\mathrm{mg} / 100 \mathrm{ml}$ ) were also evaluated. In each case an effort was made to determine the aetiology of the infectious disease by means of bacteriological techniques.

Serum creatinine, BUN, quantitative proteinuria, urinary sediment and 24-hr urine volumes were measured $7,10,14,17,21$, and 30 days after treatment started. Toxicity was determined on the basis of 3 major criteria (oliguria, $<400 \mathrm{ml} / 24 \mathrm{hr}$; serum creatinine, $0.4 \mathrm{mg}$ increase over a basal minimum of $1.2 \mathrm{mg} / 100 \mathrm{ml}$; BUN, $5 \mathrm{mg}$ increase over a minimum of $25 \mathrm{mg} / 100 \mathrm{ml}$ ); and 3 minor criteria (quantitative proteinuria higher than $750 \mathrm{mg} / 24 \mathrm{hr}$; granular casts; microscopic haematuria $>20 \mathrm{RBC}$ per high power field) in the absence of reasonable justification for these abnormalities.

In certain cases other antibiotics and diuretics were also given. The statistical study was carried out in the Centro de Cálculo de la Universidad Politécnica de Barcelona (Dr J. M. Domenech) comparing qualitative data by the $\chi^{2}$ test and quantitative data by Student's $t$ test, with a significance level at $P<0.05$.

The patients knew that they were being given a new antibiotic and that the frequency of blood extractions was for the study of the drug's possible toxicity. Patients who did not accept the protocol or from whom all the required measurements could not be obtained were excluded from the study.

\section{Results}

There were 58 male and 32 female patients of mean age 62.9 years. Infectious diseases for which the antibiotic was given were pneumonia (54 cases), urinary infection ( 24 cases), cholecystitis ( 9 cases) and septicaemia ( 3 cases). Causative agents were Pneumococcus sp. (10 cases), Escherichia coli (14 cases), Staphylococcus sp. (3 cases), Streptococcus sp. ( 3 cases), Klebsiella sp. (3 cases), Proteus sp. (2 cases), Serratia sp. (2 cases) and unknown in 53 cases. Associated significant conditions and treatment are shown in Tables 1 and 2. A total of 83 changes occurred in 35 patients $(38.8 \%)$.

Abnormalities observed were changes in serum creatinine in 18 cases $(20 \%)$, BUN in $16(17.8 \%)$, granular casts in $23(25.6 \%)$ (this being the most frequent change), haematuria in $13(14.4 \%)$, proteinuria in $10(11.1 \%)$ and oliguria in $3(3.3 \%)$. Qualitative analysis of these abnormalities shows that the change of serum creatinine and of BUN occurs simultaneously in most cases (Fig. 1).
Of 66 patients with normal renal function when the treatment was started (Group I), 13 showed changes in serum creatinine $(19.7 \%)$ and 11 on BUN $(18.7 \%)$. Mean values are shown in Fig. 2. The highest alteration occurred 14 days after treatment was started, and then the 2 values fell in parallel, becoming normal at 30 days. Of the remaining 24 patients with moderate renal insufficiency (serum creatinine $\leqslant 3 \mathrm{mg} / 100 \mathrm{ml}$ ) at the start of treatment, 5 had raised serum creatinine and BUN levels $(20.8 \%)$.

TABLE 1. Associated conditions predisposing to renal damage

\begin{tabular}{lcc}
\hline & $n$ & $\%$ \\
\hline Arterial hypertension & 11 & $12 \cdot 2$ \\
Diabetes mellitus & 12 & $13 \cdot 3$ \\
Cardiac insufficiency & 14 & $15 \cdot 6$ \\
Anaemia & 33 & $36 \cdot 7$ \\
Dehydration & 16 & $17 \cdot 8$ \\
Shock & 3 & $3 \cdot 3$ \\
Renal insufficiency & 24 & $26 \cdot 8$ \\
\hline
\end{tabular}

TABLE 2. Antibiotics and diuretics used in addition to tobramycin

\begin{tabular}{lrr}
\hline Antibiotic & $n$ & $\%$ \\
\hline Tobramycin alone & 34 & $37 \cdot 8$ \\
Cephalothin & 17 & $18 \cdot 9$ \\
Ampicillin & 22 & $24 \cdot 4$ \\
Frusemide & 4 & $4 \cdot 5$ \\
Ampicillin + frusemide & 3 & $3 \cdot 3$ \\
Lincomycin & 3 & $3 \cdot 3$ \\
Cephalothin +cloxacillin & 3 & $3 \cdot 3$ \\
Nalidixic acid +frusemide & 1 & $1 \cdot 1$ \\
Nalidixic acid & 1 & $1 \cdot 1$ \\
Nitrofurantoin & 1 & $1 \cdot 1$ \\
Carbenicillin & 1 & $1 \cdot 1$ \\
\hline
\end{tabular}

The average age of patients was significantly higher in those with changes in serum creatinine $(P<0.01)$, BUN $(P<0.005)$, microscopic haematuria $(P<0.005)$ and proteinuria $(P<0.05)$ (Fig. 3).

No significant correlation was observed between nephrotoxicity and sex, type of infection, diabetes, cardiac insufficiency, dehydration or anaemia. During the course of treatment, eosinophilia $>$ than 1000 cells $/ \mu l$ occurred in 21 patients but was not related with nephrotoxicity.

Comparison of hypertensive patients with the rest showed a higher incidence of rises in serum creatinine $(P<0.01)$, casts $(P<0.001)$ and haematuria $(P<0.001)$ in the former group (Fig. 4). Likewise, rises in BUN in patients receiving tobramycin plus ampicillin (6 of 22) were more frequent than in those treated with tobramycin only (one out of 34 ) $(P<0.005)$. However, the tobramycin-cephalothin combination did not produce a higher incidence of nephrotoxicity. 


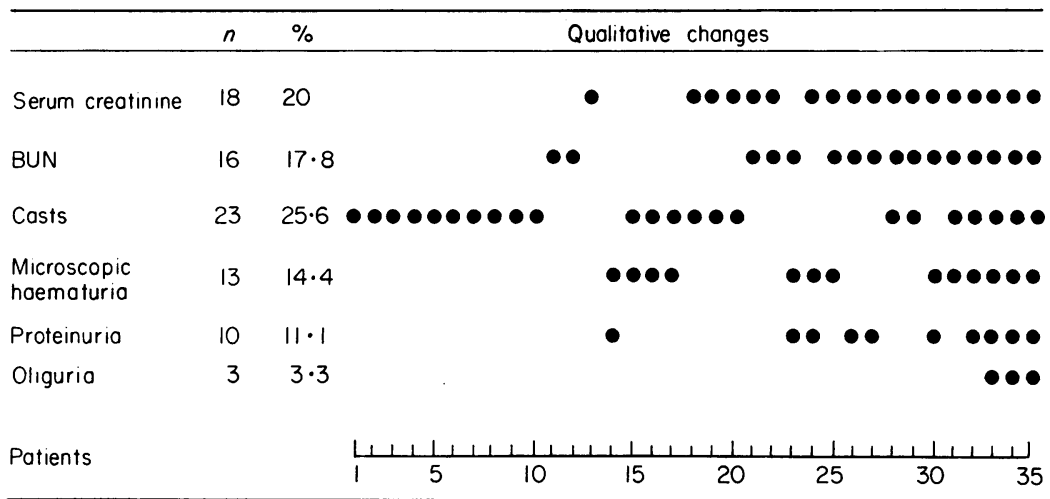

FIG. 1. Quantitative and qualitative representation of the 83 changes of renal function observed in 35 patients.

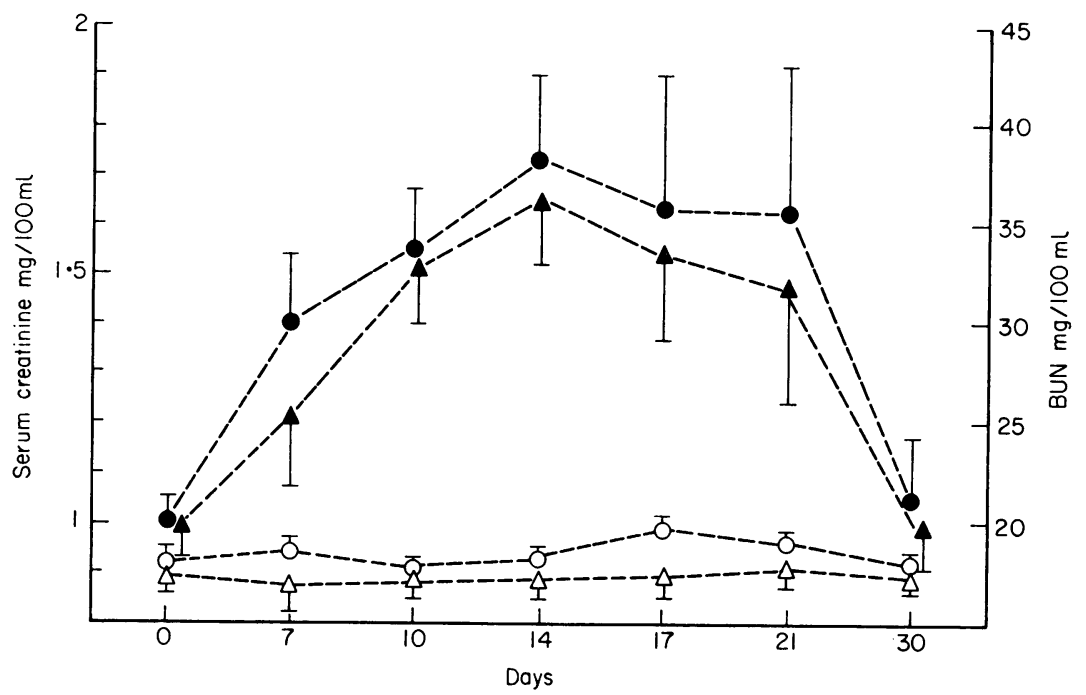

FIG. 2. Mean changes ( \pm s.e. mean) in the serum creatinine and BUN during treatment of patients with normal renal function. Increase in serum creatinine. $\Delta$ Increase in BUN. $O$ No change in serum creatinine. $\triangle$ No change in BUN.

There was an almost identical incidence of changes suggestive of nephrotoxicity in those with normal and impaired renal function before treatment.

In all patients except 3 , all changed levels returned to normal with stopping the treatment - adjustment of the dosage only was necessary. One of the 3 exceptions was an 82-year-old with chronic pyelonephritis and cardiac insufficiency who had a serum creatinine of $2 \cdot 1 \mathrm{mg} / 100 \mathrm{ml}$ at 30 days. The other 2 patients died from non-renal causes with final serum creatinine levels of $2 \cdot 8$ and $4.3 \mathrm{mg} / 100 \mathrm{ml}$.

\section{Discussion}

The administration of tobramycin to animals produces changes in the proximal tubule which, by optical and electron microscopy, are similar to those produced by gentamicin and consist of vacuolation and myeloid bodies in the tubular epithelium cell lysosomes; these changes are interpreted as the phagocytos remains of organoids from altered cells (Welles et al., 1973; De Rosa et al., 1974; Kosek, Mazze and Cousins, 1974; Szwed et al., 1974; Patel et al., 1975). The toxicity of tobramycin in man seems to be lower than that of gentamicin and 


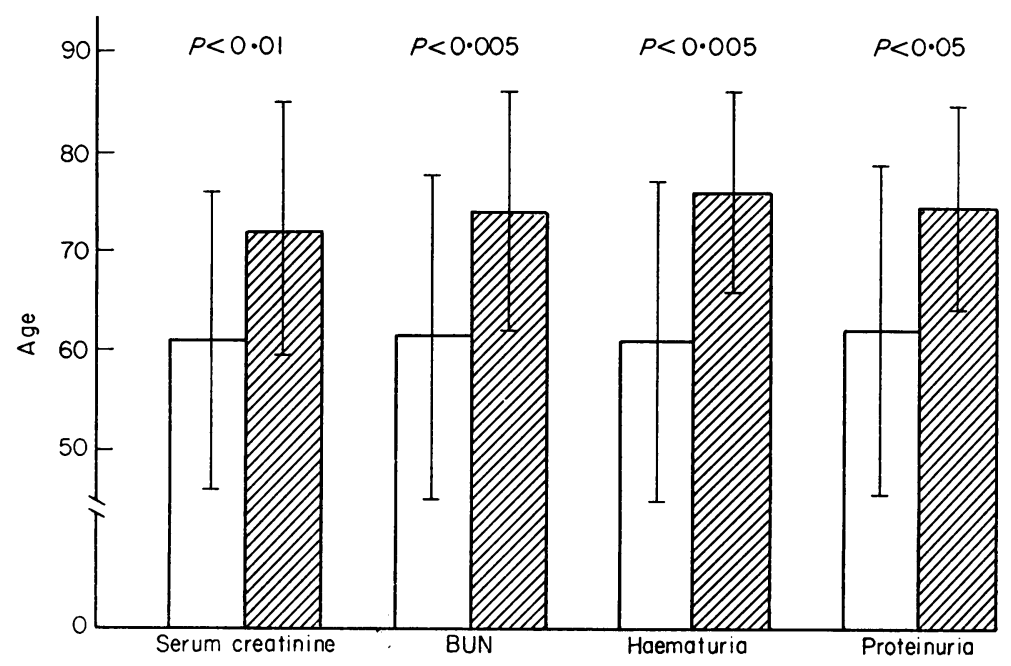

Fig. 3. Age (mean \pm 2 s.d.) of patients with $\mathbb{W}$ and without $\square$ changes.

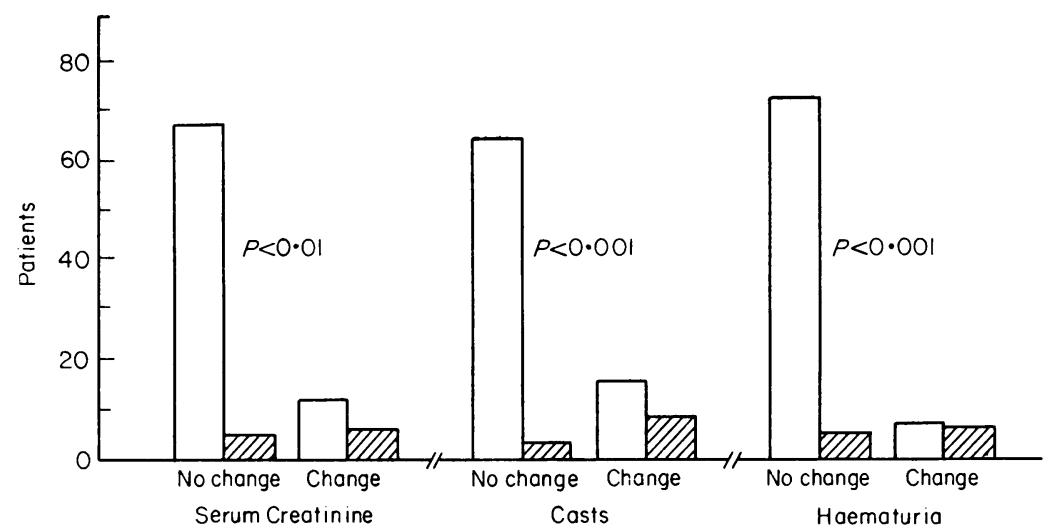

Fig. 4. Changes in laboratory findings in relation to hypertension.

ranges from 1.5 to $4.4 \%$ (Bendush and Weber, 1976; Neu, 1976) although this might be attributable to the greater care exercised when administering tobramycin, based on the previous experience with gentamicin. Toxicity is revealed by the presence of granular casts, microscopic haematuria, proteinuria, progressive azotaemia and oliguria (Appel and Neu, 1977). Cylindruria has been considered as an early sign of nephrotoxicity (Neu, 1976).

Nevertheless, there is no single criterion which is accepted by all authors as establishing antibioticinduced nephrotoxicity: Khalmeter, Kamme and Hallberg (1978) define it as progressive azotaemia and increase in serum creatinine with parallel decrease in glomerular filtration; Dosik et al. (1978) define it as an increase of $150 \%$ in serum creatinine over the initial level and a BUN increase $>40 \mathrm{mg} /$ $100 \mathrm{ml}$; Lau et al. (1977) only require a $100 \%$ increase in serum creatinine over a minimum basal level of $1.3 \mathrm{mg} / 100 \mathrm{ml}$; Lerner, Seligsohn and Matz (1977) consider a $50 \%$ increase in serum creatinine over a minimum level of $1.4 \mathrm{mg} / 100 \mathrm{ml}$; Lane, Wright and Blair (1977) require a criterion similar to that of the present authors, i.e. a $0.4 \mathrm{mg} / 100 \mathrm{ml}$ increase in serum creatinine over the basal level in patients with a serum creatinine $\leqslant 3 \mathrm{mg} / 100 \mathrm{ml}$ and 
an increase of $0.9 \mathrm{mg} / 100 \mathrm{ml}$ in patients with an initial serum creatinine $>3 \mathrm{mg} / 100 \mathrm{ml}$, as well as increases of BUN $>5 \mathrm{mg} / 100 \mathrm{ml}$ over the basal level. Finally, some authors establish this by the simple presence of casts without alterations of serum creatinine (Giamarellou et al., 1978a). All these reports support the fact that the toxicity levels defined in the literature show wide variations with a range from $1.5 \%$ (Bendush and Weber, 1976) to $48 \%$ (Giamarellou et al., 1978a) depending on the criterion used.

In the present study, only 3 patients, all seriously ill, 2 of whom died, showed oliguria with progressive azotaemia. One had neoplastic disease in which nephrotoxicity is most likely to occur (Klastersky, Hensgens and Debusscher, 1975; Plager, 1976). On the basis of this criterion the toxicity in this series was only $3.3 \%$. In accordance with the criterion of Dosik et al. it was $4.4 \%$, according to Lau et al., $6.6 \%$, according to Lerner's $13.3 \%$, based on the present authors' main criteria and those of Lane et al. $20 \%$; and, finally, according to the present authors' minor criteria or those accepted by Giamarellou et al., (1978a), $38.8 \%$. This is why, although $38.8 \%$ of the patients presented some kind of change of the parameters studied, only $20 \%$ of them required dosage adjustment because of increases in serum creatinine. Cylindruria, the most frequent abnormality, did not correlate with the other changes in most of the cases.

As already noted by other authors (Kleinknecht and Juggers, 1973; Kahlmeter et al., 1978) age and arterial hypertension were related to a higher incidence of changes in some of the parameters studied. Those patients with moderate renal insufficiency on initiation of treatment did not show a higher degree of toxicity, in contrast with the findings of others (Appel and Neu, 1977); this is attributed to the strict control of serum creatinine levels and subsequent dosage adjustments.

In the last years, many cases of nephrotoxicity have been reported after using an aminoglycoside with other antibiotics, particularly the association gentamicin-cephalothin (Bobrow, Jaffe and Young, 1972; Fillastre, 1973; Fillastre et al., 1973; Kleinknecht and Juggers, 1973; Kleinknecht, Ganeval and Droz, 1973; Mendez and Ortiz, 1974; Plager, 1976). Cephalothin, when given in high dosage, can produce proximal tubular lesions and acute tubular necrosis in animals (Carling et al., 1975) and in man (Burton et al., 1974; Engle et al., 1975; Pasternak and Stephens, 1975). However, certain experimental (Carling et al., 1975) as well as clinical studies do not confirm such a hypothesis (Fanning, Jick and Gump, 1975; Gaya, Klastersky and Schimpff, 1975; Giamarellou et al., 1978b). In the present study no differences were observed between those patients receiving tobramycin only or tobramycin plus cephalothin. Ampicillin nephrotoxicity has been reported (Benner, 1970). The present authors found a higher degree of toxicity when ampicillin was associated with tobramycin. As far as they know, the latter has not previously been reported.

From the results obtained it can be concluded that the nephrotoxicity of tobramycin ranges from 3.3 to $38.8 \%$ depending on the criterion used. On the basis of main criteria it reaches a maximum of $20 \%$ and it subsides spontaneously without need for discontinuing the antibiotic in $96.7 \%$ of the cases. The presence of moderate renal insufficiency on starting treatment does not predispose to toxicity provided dosage is adjusted.

\section{References}

Alcazar, J.M., Resano, M., Alles, A. \& Valderrabano, F. (1976) Antibióticos nefrotóxicos como causa de fracaso renal agudo. (abstract). IX Reunión Nacional de Nefrología, Valencia, España, p. 30.

APPEL, G.B. \& NEU, H.C. (1977) The nephrotoxicity of antimicrobial agents. New England Journal of Medicine, 296, 722.

Bendush, C.L. \& Weber, R. (1976) Tobramycin sulfate: a summary of worldwide experience from clinical trials. Journal of Infectious Diseases, 134 (suppl), 219.

BENNER, E.J. (1970) Renal damage associated with prolonged administration of ampicillin, cephaloridine and cephalothin. Proceedings of the 9 th Interscience Conference on Antimicrobial Agents and Chemotherapy, Washington, October 1969, p. 417.

BenNer, E.J., Kranhold, J. \& Bush, W. (1974) Tobramycin : in vitro activity, dosage nomogram derived from renal handling and clinical efficacy. Proceedings from the Eighth International Congress of Chemotherapy, Athens, p. 16.

Bobrow, S.N., JAFFE, E. \& Young, R.C. (1972) Anuria and acute tubular necrosis associated with gentamicin and cephalothin. Journal of the American Medical Association, 222, 1546.

BritT, M.R., Garibaldi, R.A., Wilfert, J.N. \& SMith, C.B. (1972) In vitro activity of tobramycin and gentamicin. Antimicrobial Agents and Chemotherapy, 2, 236.

Burton, J.R., Lichtenstein, N.S., Colvin, R.B. \& Hyslop, N.E. (1974) Acute renal failure during cephalothin therapy. Journal of the American Medical Association, 229, 679.

Carling, P.C., Idelson, B.A., Casano, A.A., Alexander, E.A. \& MCCABE, W.R. (1975) Nephrotoxicity associated with cephalothin administration. Archives of Internal Medicine, 135, 79\%.

Delbene, V.E. \& Farrar, W.E. (1972) Tobramycin: in vitro activity and comparison with kanamycin and gentamicin. Antimicrobial Agents and Chemotherapy, 1, 340.

DE Rosa, F., Buoncristiani, V., CAPitanuCCI, P. \& FrongILlo, R.F. (1974) Tobramycin: toxicological and pharmacological studies in animals and pharmacokinetic research in patients with varying degrees of renal impairment. Journal of International Medical Research, 2, 100.

Dosik, G.M., Gutterman, J.U., Hersh, E.M., Akhtar, M., SonodA, T. \& HoRN, R.G. (1978) Nephrotoxicity from cancer inmunotherapy. Annals of Internal Medicine, 89, 41.

DUNCAN, I.B.R. \& PENNER, J.L. (1975) Comparative activity of tobramycin and gentamicin against Pseudomonas, Proteus and Providentia species. Canadian Medical Association Journal, 113, 1. 
Engle, J.E., Drago, J., Carlin, B. \& Schoolwerth, A.C. (1975) Reversible acute renal failure after cephalothin. Annals of Internal Medicine, 83, 232.

FANNING, W.L., JICK, H. \& GUMP, D.W. (1975) Rising BUN with gentamicin, cephalothin or both (abstract). Proceedings of the 15th International Conference on Antimicrobial Agents and Chemotherapy, Washington (1974), p. 402.

Fillastre, J.P. (1973) Acute renal failure associated with combined gentamicin and cephalothin therapy. British Medical Journal, 2, 396.

Fillastre, J.P., Laumonier, R., Humbert, G., Dubois, D., METAYER, J. \& DELPECH, A. (1973) Insuffisances rénales aiguës après administration de céphalotine et gentamicine. Nouvelle Presse Médicale, $2,444$.

Gaya, H., Klastersky, J. \& SchimpfF, S.C. (1975) Nephrotoxicity during combined therapy with gentamicin and cephalothin (abstract). Proceedings of the 15th International Conference on Antimicrobial Agents and Chemotherapy, Washington (1974), p. 401.

Giamarellou, H., Papachristophorou, S., Hadjipapas, M., Metzikoff, CH., Dontas, A.S. \& Daikos, G.K. (1978a) Prospective comparison of gentamicin versus tobramycin nephrotoxicity in humans (abstract). First Mediterranean Congress of Chemotherapy, Madrid, p. 59.

Giamarellou, H., Metzikoff, CH., Papachristophorou, S., Petrikkos, G. \& Daikos, G.K. (1978b) Nephrotoxicity of cephalothin plus gentamicin combination in humans (abstract). First Mediterranean Congress of Chemotherapy, Madrid, p. 60.

HoF, G.E., Schiotz, P.O. \& PAulsen, J. (1974) Tobramycin treatment of Pseudomonas aeruginosa infections in cystic fibrosis. Scandinavian Journal of Infectious Diseases, 6, 333.

Hollenberg, N.K., Adams, D.F., OKen, D.E., Abrams, H.L. \& MerRILL, J.P. (1970) Acute renal failure due to nephrotoxins. Renal hemodynamic and angiographic studies in man. New England Journal of Medicine, 282, 1329.

Jaffe, G., Ravreby, W., Meyers, B.R. \& Hirschman, S.Z. (1974) Clinical study of the use of the new aminoglycoside tobramycin for therapy of infections due to Gramnegative bacteria. Antimicrobial Agents and Chemotherapy, 5, 75.

Kahlmeter, G., Kamme, C. \& Hallberg, T. (1978) Nephrotoxicity of gentamicin and tobramycin. A comparison in patients with various infections (abstract). First Mediterranean Congress of Chemotherapy, Madrid, p. 59.

Klastersky, J., Hensgens, C. \& Debusscher, L. (1975) Empiric therapy for cancer patients: comparative study of ticarcillin-tobramycin, ticarcillin-cephalothin and cephalothin-tobramycin. Antimicrobial Agents and Chemotherapy. 7, 640 .

KleinkneCht, D. \& Juggers, D. (1973) Açcident rénal aigu au cours d'un traitement par la gentamicine et la céphalotine. Nouvelle Presse Médicale, 2, 25.

Kleinknecht, D., Ganeval, D. \& Droz, D. (1973) Acute renal failure after high doses of gentamicin and cephalothin. Lancet, i, 1129.

Kosek, J.C., MAzze, R.I. \& Cousins, M.J. (1974) Nephrotoxicity of gentamicin. Laboratory Investigation, 30, 48.

Landes, R.R., Melnick, I., Hoffman, A. \& Fehrenbaker, L. (1975) Tobramycin, a new aminoglycoside antibiotic:
Experience in urinary tract infections. Southern Medical Journal, 68, 116.

LANE, A.Z., Wright, G.E. \& BlaIR, D.C. (1977) Ototoxicity and nephrotoxicity of amikacin. An overview of phase II and phase III experience in the United States. American Journal of Medicine, 62, 911.

LAU, W.K., Young, L.S., BLACK, R.E., Winston, D.J., LinNe, S.R., Weinstein, R.J. \& HeWITt, W.L. (1977) Comparative efficacy and toxicity of amikacin-carbenicillin versus gentamicin-carbenicillin in leukopenic patients. American Journal of Medicine, 62, 959.

Lerner, S.A., Seligsohn, R. \& Matz, G.J. (1977) Comparative clinical studies of ototoxicity and nephrotoxicity of amikacin and gentamicin. American Journal of Medicine, $62,919$.

Lockwood, W.R. \& Bower, J.D. (1973) Tobramycin and gentamicin concentrations in the serum of normal and anephric patients. Antimicrobial Agents and Chemotherapy, 3, 125.

Mendez, A. \& Ortiz, A. (1974) Fracaso renal agudo por la asociación de cefalotina y gentamicina. Revista Clínica Española, 133, 365.

NeU, H.C. (1976) Tobramycin: an overview. Journal of Infectious Diseases, 134 (suppl), 3.

PASTERnAK, D.R. \& Stephens, B.G. (1975) Reversible nephrotoxicity associated with cephalothin therapy. Archives of Internal Medicine, 135, 599.

Patel, V., LufT, F., YUM, H. \& KLeIT, S. (1975) Lysosomal enzyme markers in gentamicin and tobramycin nephrotoxicity (abstract) Proceedings of the 15th International Conference on Antimicrobial Agents and Chemotherapy, Washington (1974), p. 398.

Pennington, J.E. \& ReYnolds, H.Y. (1973) Tobramycin in bronchial secretions. Antimicrobial Agents and Chemo@ therapy, 4, 299.

Plager, J.E. (1976) Association of renal injury with com bined cephalothin-gentamicin therapy among patients: severely ill with malignant disease. Cancer, 37, 1937.

Preston, D.A. \& WiCK, W.E. (1971) Preclinical assessment of the antibacterial activity of nebramycin factor 6 . Proceedings of the 10th International Conference on Antimicrobial Agents and Chemotherapy, Chicago, October 1970, p. 322.

SzWed, J.J., LuFT, F.C., BlaCK, H.R., ElliotT, R.A. \& KLEIT, S.A. (1974) Comparison of the distribution of tobramycin and gentamicin in the body fluids of dogs. Antimicrobial Agents and Chemotherapy, 5, 444.

Tobias, J.S., Whitehouse, J.M. \& WRIGLeY, P.F.M. (1976) Severe renal dysfunction after tobramycin-cephalothin therapy. Lancet, i, 425.

Welles, J.S., Emmerson, J.L., Gibson, W.R., Niekander, R., OWen, N.V. \& Anderson, R.C. (1973) Preclinical toxicologic studies with tobramycin. Toxicology and Applied Pharmacology, 25, 398.

WICK, W.E. \& WeLles, J.S. (1968) Nebramycin, a new broadspectrum antibiotic complex. IV. In vivo and in vitro laboratory evaluation. Proceedings of the 7th International Conference on Antimicrobial Agents and Chemotherapy, Chicago, October 1967, p. 341. 